\title{
PENGARUH EDUKASI TERHADAP PENGELOLAAN DIABETES LANSIA DI POSBINDU KELURAHAN KARANGSARI KOTA TANGERANG TAHUN 2018
}

\author{
Rohanah, Lailatul Fadilah \\ Poltekkes Kemenkes Banten \\ Korespondensi: rohanah@poltekkesbanten.ac.id
}

\begin{abstract}
Diabetes mellitus is one of the common diseases in the elderly, almost $50 \%$ of patients with type 2 diabetes are over 65 years old. Diabetes in the elderly affects the quality of life of the elderly. The education referred to in this study is to provide health education to the elderly about how to live healthy with diabetes and prevent complications. The four pillars of diabetes management are education, meal planning, physical exercise, pharmacological intervention. The purpose of this study was to determine the effect of education on increasing knowledge and behavior so that the elderly were able to manage diabetes. The hypothesis of this study is that there is an effect of education on increasing knowledge and behavior so as to improve the ability of the elderly to manage diabetes. The study was conducted in Posbindu Karangsari Village, Tangerang City in 2018 with a sample of 30 elderly people as an intervention group and 30 elderly as a control group. The design and methodology of this study used Quasi experimental prepost test. These data were analyzed using the dependent $t$ test and independent $t$ test. The results showed that there was a significant effect of the educational process on increasing knowledge and behavior in the intervention group with a value of $p$ value 0.00 and there was a significant effect of intervention group education compared to the control group with a knowledge value of p value 0.02 and a behavioral value of 0.003 . Conclusion: there is an influence of education on increasing knowledge and behavior in elderly who have diabetes mellitus.
\end{abstract}

Keywords: Education, Managing diabetes, Elderly

\begin{abstract}
ABSTRAK
Diabetes mellitus merupakan salah satu penyakit yang sering dijumpai pada usia lanjut, hampir 50\% pasien diabetes tipe 2 berusia diatas 65 tahun. Diabetes pada lansia pada akhirnya mempengaruhi kualitas hidup lansia. Edukasi yang dimaksud dalam penelitian ini adalah memberikan pendidikan kesehatan kepada lansia tentang cara hidup sehat dengan diabetes serta mencegah terjadinya komplikasi. Empat pilar pengelolaan diabetes yaitu edukasi, perencanaan makan, latihan jasmani, intervensi farmakologi. Tujuan penelitian ini untuk mengetahui pengaruh edukasi terhadap peningkatan pengetahuan dan perilaku sehingga lansia mampu mengelola diabetes. Hipotesa penelitian ini ada pengaruh edukasi terhadap peningkatan pengetahuan dan perilaku
\end{abstract}


sehingga meningkatkan kemampuan lansia mengelola diabetes yang dialaminya.. Penelitian ini dilakukan di Posbindu Kelurahan Karangsari kota Tangerang tahun 2018 dengan sampel 30 orang lansia sebagai kelompok intervensi dan 30 lansia sebagai kelompok kontrol. Desain dan metodologi penelitian ini menggunakan Quasi eksperimen pre - post test. Data dianalisis menggunakan Uji dependent. $t$ test dan independent $t$ test. Hasil penelitian menunjukan ada pengaruh yang signifikan proses edukasi terhadap peningkatan pengetahuan dan perilaku pada kelompok intervensi dengan nilai $\mathrm{p}$ value 0.00 dan ada pengaruh signifikan edukasi kelompok intervensi dibandingkan dengan kelompok control dengan nilai pengetahuan $p$ value 0.02 dan nilai perilaku 0.003. kesimpulan : ada pengaruh edukasi terhadap peningkatan pengetahuan dan perilaku pada lansia yang mengalami Diabetes Melitus.

\section{Kata Kunci : Edukasi, Lansia, Pengelolaan Diabetes.}

\section{PENDAHULUAN}

Jumlah lansia yang semakin meningkat menunjukan kemajuan dibidang kesehatan dan pembangunan nasional. Dengan meningkatnya usia harapan hidup berarti juga meningkat masalahmasalah kesehatan yang harus dihadapi baik oleh keluarga,masyarakat dan lebih jauh oleh pemerintah. Lansia dengan proses menurunnya fungsi-fungsi tubuh yang diikuti oleh penurunan fungsi kognitif dan psikomotor akan berdampak pada kehidupan sehari-hari Data terakhir tahun 2014 jumlah penduduk lansia mencapai 20,24 juta jiwa setara dengan $8,03 \%$ dari seluruh jumlah penduduk Indonesia 2014. diperkirakan meningkat tahun 2035 mencapai 41 juta jiwa. Indonesia sebagai negara kelima terbanyak lansia, maka membutuhkan perhatian dan perlakuan khusus agar para lansia tetap menjadi masyarakat yang sehat produktif minimal untuk dirinya sendiri.

Menua adalah proses alami yang harus dilalui oleh semua mahluk hidup yang tidak dapat dihindari, dan merupakan hal yang wajar dialami diperkirakan meningkat tahun 2035 mencapai 41 juta jiwa. Indonesia sebagai negara kelima terbanyak lansia, maka membutuhkan perhatian dan perlakuan khusus agar para lansia tetap menjadi masyarakat yang sehat produktif minimal untuk dirinya sendiri.

Usia 60 tahun keatas merupakan tahap akhir dari proses penuaan yang memiliki dampak terhadap tiga aspek yaitu biologis,sosial,ekonomi .negara perlu memberikan perlindungan kepada lansia agar dapat meminimalkan dampak penurunan fungsi -fungsi sehingga 
lansia masih dapat berfungsi secara aktif dan produktif baik dalam lingkungan keluarga maupun lingkungan yang lebih luas.Banyak teori mengatakan penduduk sebagai salah satu faktor strategis dalam mendukung pembangunan nasional, lansia juga bagian dari masyarakat yang masih dapat berfungsi sebagai objek dan subjek pembangunan bila para lansia itu sehat dan sejahtera. Tapi banyak masalah yang dihadapi lansia seiring dengan kemunduran yang terjadi sehingga beberaabenyakit juga menyertai kehiduan lansia salah satunya adalah diabetes mellitus.

Hamir 50\% dibetes tye 2 diberusia diatas 65 tahun keatas,diabetes pada lansia berbeda secara metabolic denngan diabetes pada kelompok usia lain. Data terbaru tahun 2015 yang ditunjukan oleh perkumpulan endokrinologi (PERKENI) bahwa jumlah penderita diabetes Melitus di Indonesia mencapai 9,1 juta jiwa atau peringkat ke 5 dunia.Penderita diabetes yang berusia 60-79 tahun berjumlah 2 juta orang . Lansia yang menderita diabetes memerlukan perawatan yang berbeda dengan usia muda, hal ini diakibatkan lansia seringkali mengalami penyakit lain sebagai dampak ketuaannya.seperti ketidakmampuan fisik, gangguan kognitif, gangguan psikososial, yang pada akhirnya komplikasi yang terjadi akan menurunkan kualitas hidupnya.

Penyakit diabetes pada lansia bukan berarti tidak dapat diatasi tetapi masih ada kemungkinan kondisi lebih baiok bila lansia mampu mengelola kondisi penyakitnya sehingga lansia masih dapat hidup sehat bahagia,dan produktif.Oleh karena itu lansia perlu diberikan edukasi tentang pengelolaan diabetes dengan meningkatkan pengetahuan dan perilaku hidup sehat.

Peneliti akan melakukan edukasi tentang cara mengelola diabetes pada lansia dengan tujuan lansia terhindar dari komplikasi dengan tujuan jangka panjang adalah mencapai kualitas hidup yang optimal. Penelitian serupa telah dilakukan oleh Stella Leoni Kecek dari Universitas Samratulangi tahun 2017 tentang gambaran kualitas hidup lansioa dengan DM didapatkan hasil bahwa lansia tanpa DM akan lebih baik kualitas hidupnya.

Dilingkungan RW 13 Kelurahan Karangsar terdapat Posbindu denghan jumlah lansia 78 orang.sementara yang menderita DM ada 30 orang dengan kondisi belum pernah diberikan edukasi dan belum mengerti tentang cara mengelola /mengatur hidup dengan DM . 
Oleh karena itu peneliti ingin melakukan edukasi untuk para lansia tersebut.

\section{METODE}

Penelitian ini merupakan penelitian kuantitatif dengan desain penelitian pre test-post test control group design. Data dianalisis menggunakan analisis univariat dan bivariat Kegiatan penelitian ini menggunakan alat ukur berupa kuesioner untuk mengetahui pengetahuan dan perilaku lansia sebelum dan sesudah dilakukan edukasi di Kelurahan Karangsari Kota Tangerang tahun 2018.

Analisis univariat digunakan untuk mengetahui distribusi frekwensi karakteristik responden. Analisis bivariat menggunakan Uji dependen $t$ test dan independen $t$ test untuk mengetahui pengaruh edukasi terhadap pengelolaan diabetes lansia

\section{HASIL}

Hasil pada penelitian ini dapat dibedakan berdasarkan analisis univariat dan bivariat seperti berikut ini:

\section{Analisis Univariat;}

Tabel 1

Distribusi Frekwensi Responden Berdasarkan Karakteristik Responden

\begin{tabular}{lcc} 
Karakteristik & Frekwensi & Persentasi \\
Umur & & \\
$60-65$ & 15 & $50 \%$ \\
$66-70$ & 13 & $43 \%$ \\
$>70$ & 2 & $7 \%$ \\
Pendidikan & & \\
$\begin{array}{l}\text { Rendah(SD.SMP) } \\
\text { Tinggi(SMA,PT) }\end{array}$ & 24 & $80 \%$ \\
Pekerjaan & 6 & $20 \%$ \\
Tidak Bekerja & 25 & $83 \%$ \\
$\begin{array}{l}\text { Bekerja } \\
\text { Jenis Kelamin }\end{array}$ & 5 & $17 \%$ \\
$\quad$ Laki-laki & 10 & $33 \%$ \\
Perempuan & 20 & $67 \%$ \\
\hline
\end{tabular}

Dari gambaran data diatas menunjukan secara umum jenis kelamin lebih banyak wanita dengan umur 60-65 dan lebih banyak yang tidak bekerja dan berpendidikan rendah .

\section{Analisa bivariat}

Tabel 2

Perbandingan Nilai pengetahuan dan perilaku pada kelompok intervensi dan kelompok kontrol Sebelum Dan Sesudah Diberikan Edukasi Pada Lansia di Kelurahan Karangsari Tangerang

\begin{tabular}{ccccccc}
\hline Variabel & \multicolumn{3}{c}{ Pengetahuan } & \multicolumn{3}{c}{ Perilaku } \\
\cline { 2 - 7 } & Mean & SD & $\begin{array}{c}\text { Min- } \\
\text { max }\end{array}$ & Mean & SD & $\begin{array}{c}\text { Min- } \\
\text { max }\end{array}$ \\
\hline $\begin{array}{c}\text { Kelompok } \\
\text { Intervensi }\end{array}$ & & & & & & \\
\hline Pre Ed & $\mathbf{1 3 , 7 0}$ & $\mathbf{2 , 9 5}$ & $\mathbf{6 - 1 9}$ & $\mathbf{5 3 , 1 3}$ & $\mathbf{9 , 9 4 0}$ & $\mathbf{1 6 - 3 0}$ \\
\hline Post Ed & $\mathbf{1 6 , 7 7}$ & $\mathbf{2 , 0 9}$ & $\mathbf{1 2 - 2 0}$ & $\mathbf{5 7 , 7 3}$ & $\mathbf{1 0 , 6 9}$ & $\mathbf{1 5 - 7 5}$ \\
\hline $\begin{array}{c}\text { Kelompok } \\
\text { Kontrol }\end{array}$ & & & & & & \\
\hline Pre Ed & $\mathbf{1 4 , 8 0}$ & $\mathbf{2 , 2 0}$ & $\mathbf{1 0 - 1 9}$ & $\mathbf{5 5 , 5 0}$ & $\mathbf{7 , 0 8}$ & $\mathbf{4 1 - 6 5}$ \\
\hline Post $E d$ & $\mathbf{1 5 , 3 3}$ & $\mathbf{2 , 1 5}$ & $\mathbf{1 0 - 1 9}$ & $\mathbf{5 5 , 4 7}$ & $\mathbf{6 . 6 6}$ & $\mathbf{4 1 - 6 4}$ \\
\hline
\end{tabular}


Pada Tabel 2 Menunjukan bahwa nilai rerata pengetahuan pada kelompok intervensi sebelum edukasi adalah 13,7 dan sesudah edukasi 16,77. Sedangkan nilai perilaku pada kelompok intervensi sebelum dilakukan edukasi adalah53,73 dan sesudah dilakukan edukasi adalah 57,73 .

Pada kelompok kontrol nilai pengetahuan sebelum dilakukan edukasi adalah 14,8 dan sesudah 15,3 sedangkan nilai perilaku kelompok kontrol sebelum silakukan edukasi adalah 55,50 dan sesudah 55,47

Tabel. 3

Perbedaan Rerata Nilai pengetahuan Pada Kelompok Intervensi Dan Kelompok Kontrol Sebelum Dan Sesudah Dilakukan Edukasi
Tabel. 4

Perbedaan Rerata Nilai Perilaku Pada

Kelompok Intervensi Dan Kelompok Kontrol Sebelum Dan Sesudah Dilakukan Edukasi

\begin{tabular}{lcccccc}
\hline Variabel & KLP & Mean & SD & df & t & P value \\
\hline Perilaku & $\begin{array}{c}\text { Inter } \\
\text { vensi }\end{array}$ & & & & & \\
\hline Sebelum & & $\mathbf{5 3 , 1 3}$ & $\mathbf{9 , 9 4}$ & $\mathbf{2 9}$ & $\mathbf{- 5 4 6 1}$ & $\mathbf{0 , 0 0}$ \\
\hline Sesudah & & $\mathbf{5 7 , 7 3}$ & $\mathbf{1 0 , 6 0}$ & & & \\
\hline $\begin{array}{l}\text { Perbeda } \\
\text { an }\end{array}$ & & $\mathbf{4 , 6 0}$ & $\mathbf{0 , 7 5}$ & & & \\
\hline & Kon & & & & & \\
\hline trol & & & & & \\
\hline Sebelum & & $\mathbf{5 5 , 5 0}$ & $\mathbf{7 , 0 8 9}$ & $\mathbf{2 9}$ & $\mathbf{- 5 , 5 9}$ & $\mathbf{0 , 9 3 1}$ \\
\hline $\begin{array}{l}\text { Pesudah } \\
\text { an }\end{array}$ & & $\mathbf{5 5 , 4 7}$ & $\mathbf{6 , 6 6 3}$ & & & \\
\hline
\end{tabular}

Tabel 4 Menunjukan rata -rata nilai perilaku pada kelompok intervensi sebelum dilakukan edukasi adalah 53,13 dan sesudah edukasi adalah 57.73, Analisa lebih lanjut dapat dikatakan ada perbedaan signifikan sebelum dan

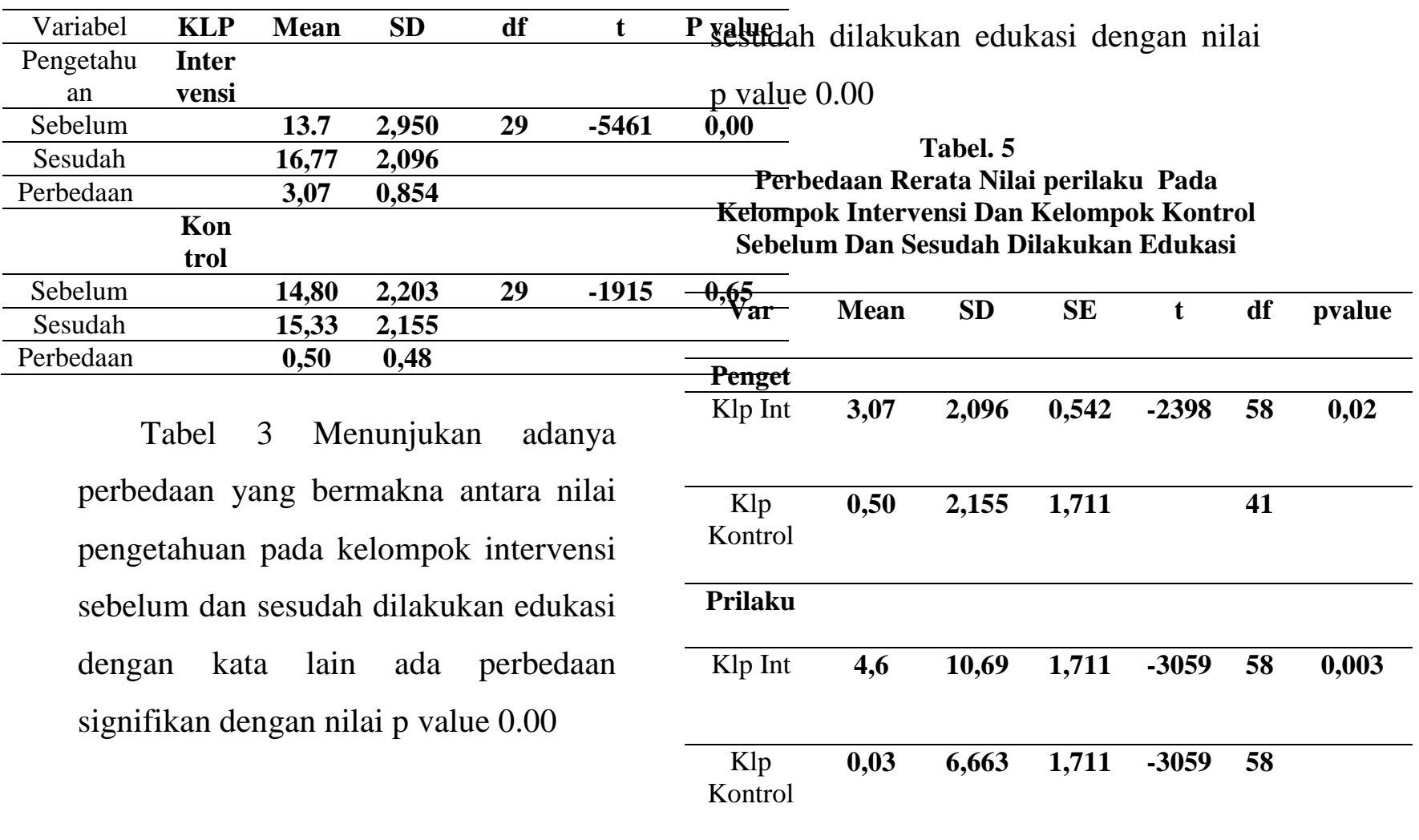


Tabel 5 menunjukan ada perbedaan yang signifikan antara nilai pengetahuan klp intervensi dengan kelompok kontrol dengan nilai $\mathrm{p}$ value 0,02 dan pada nilai perilaku ada perbedaan signifikan pada kelompok intervensi dengan nilai $\mathrm{p}$ value 0,003 .

\section{PEMBAHASAN}

Gambaran data Univariat dihubungkan dengan variabel pengetahuan dan perilaku ternyata tidak ada hubungan yang bermakna karena semua nilai criteria dari respondern (umur,jenis kelamin,pendidikan ,lama menderita DM) dengan nilai diatas 0,05 dapat disimpulkan bahwa pada kelompok intervensi tidak ada hubungan bermakna antara criteria responden dengan pengetahuan dan perilaku lansia.

Gambaran angka rerata nilai pengetahuan pada kelompok intertvensi sebelum dan sesudah ada peningkatan dari 13,70 menjadi 16,77 dan nilai prilaku sebelum edukasi dari 53,13 menjadi 57,73 setelah dilakukan edukasi.

Analisa lebih lanjut dapat dikatakan bahwa ada peningkatan yang signifikan untuk variabel pengetahuan dengan nilai $\mathrm{p}$ value 0,00 dan variabel perilaku pada kelompok intervensi dengan nilai $\mathrm{p}$ value 0,00. Hal ini sesuai dengan penelitian
Muhtarom 2017 tentang pengaruh pendidikan kesehatan terhadap tingkat pengetahuan penderita DM tipe 2 di Desa Ngadiwarno Sukarejo Kendal dengan nilai $p$ value 0,00

Gambaran perbedaan rerata nilai pengetahuan antara kelompok intervensi dan kelompok kontrol setelah dilakukan edukasi yaitu pada kelompok intervesi perbedaan rerata dengan nilai 3,07 dan pada kelompok kontrol perbedaan rerata adalah 0,50 Analisa lebih lanjut ada perbedaan yang signifikan selisih rerata antara kelompok intervensi dan kelompok kontrol dengan nilai $\mathrm{p}$ value 0,02.Pada kelompok intervensi terlihat ada peningkatan pengetahuan sedangkan pada kelompok kontrol ada peningkatan tapi tidak signifikan. Sehingga dapat dikatakan bahwa edukasi dapat meningkatkan pengetahuan lansia tentang pemngelolaan diabetes.

Perbedaan rerata peningkatan nilai perilaku pada kelompok intervensin adalah 4,6 sedangkan pada kelompok kontrol 0,03. Hasil analisis lebih lanjut dapat dikatakan ada perbedaan yang signifoikan selisih rerata nilai perilaku antara kelompok intervensi dan kelompok kontrol dengan nilai $p$ value 0,003 .

Pada kelompok intervensi ada peningkatan yang signifikan sedangkan 
pada kelompok kontrol ada peningkatan tapi tidak signifikan.

Hal ini sesuai dengan penelitioan Dyah Restuning Putri tentang efektifitas Edukasi diabetes dalam meningkatkan kepatuhan diet pada DM tipe 2 di Kelurahan Wirogunan Jogja dengan hasil penelitian bermakna dengan nilai $\mathrm{p}$ value 0,02

\section{SIMPULAN}

Ada hubungan yang signifikan selisih rerata antara ke;lompok intervensi dan kelompok kontrolpada angka pengetahuan dengan nilai $\mathrm{p}$ value 0,02 dan ada perbedaan yang signifikan antara kelompok intervensi dan kelompok kontrol pada angka perilaku dengan nilai $\mathrm{p}$ value 0.003 .

Ada pengaruh yang signifikan pada edukasi terhadap peningkatan pengetahuan dan perilaku lansia dengan diabetes mellitus.

\section{DAFTAR PUSTAKA}

1. Ali Maghfuri (2016) Perawatan Luka Diabetes Melitus penerbit Salemba medika

2. Anis dkk (2016) Kualitas Hidup lansia FIK Muhamadiyah Malang, Jurnal keperawatan ISSN 2086-3071 Diunduh 7 Juni 2017

3. Dyah Restuning $\mathrm{P}$ Efektifitas Edukasi Diabetes Dalam Meningkatkan
KepatuhanPengaturandiet Pada DM Tipe 2di Kelurahan Wirogunan Jogjakarta http://journal.umy.ac.id/index.php /mm/article/viewFile/2492/2556 Di unduh jam 17.30 tanggal 20 Nopember 2018

4. Marifatul Azizah( 2011) Keperawatan Lanjut Usia Edisi $2 E G C$

5. Prof Dr dr askandar Cokroprawiro Sp Pd, K.EMD.FINASIM : Hidup Sehat Bersama Diabetes Melitus Panduan Lengkap Pola Makan

6. Muhtarom (2017) Pengaruh Pendidikan Kesehatan Terhadap tingkat pengetahuan penderita DM tipe 2 di Desa Sukorejo Kendal PSIK UIN Syarif hidayatullah jakarta

7. SidartaSoegondo

Penatalaksanaan DM Terpaadu Edisi 2 ,(Panduan Untuk Dokter dan Ediukator) Penerbit U I Press

8. Stella Laoni Kesek (2017) Gambaran Kualitas Hidup Lansia Dengan DM dan Tanpa DM Di Kelurahan Kinilon Kecamatan Tomohon Utara Manado FKM Samratulangi

9. Kementrian Keuangan RI. Penduduk Lansia DanBonus Demografi Kedua. http//www.go.id Diunduh 15-102017 jam 11.53

10. Yunitasari Ns,MHS,PhD :(2015) Perawatan Luka berdasarkan Konsep manajemen Luka Modern Dan Penelitian Terkini Penerbit Graha Ilmu Empat pilar Pengelolaan Diabetes mellitus www//smallcrab.com/informasi kesehatan diunduh 15-10-2017 jam 21.30 
11. sehat.link/data -prevalensipenderita-diabetes-diIndonesia.info (2015)

12. Wahyudi Nugroho (2008) Keperawatan Gerontik Edisi 3 EGC 